Cuttle, T. D. (1938). Quart. J. Med. 31, 575.

Franke, M. \& Horwitz, S. (1938). Z. Geburtsh. Gynäk. 108, 318.

Hagtvet, J. (1945). Skr. norske VidenskAkad. 2, 1. Quoted in Chem. Abstr. (1947). 41, $796 \mathrm{c}$.

Hess, A. F. (1920). Scurvy-Past and Present. Philadelphia: Lippincott and Co.

Humphrey, J. H. \& Jaques, R. (1954). J. Physiol. 124, 305.

Lawrynowicz, A. (1931). J. Physiol. Path. gén. 29, 270.

Mindlin, R. C. \& Butler, A. M. (1937). J. biol.Chem.122, 673.

Nungester, W. J. \& Ames, A. M. (1948). J. infect. Dis. 83, 50.

Olef, I. (1937). J. Lab. clin. med. 23, 166.

Penney, J. R. \& Balfour, B. M. (1949). J. Path. Bact. 61, 171.

Roe, J. H. \& Kuether, C. A. (1943). J. biol. Chem. 147, 399.
Roos, J. (1957). Thromb. Diath. Haemorr. 1, 471.

Sebrell, W. H. \& Harris, R. S. (1954). The Vitamins, vol. 1, p. 362. New York: Academic Press Inc.

Stephen, P. J. \& Hawley, E. F. (1936). J. biol. Chem. 115, 653.

Tivey, H., Li, J. G. \& Osgood, E. E. (1951). Blood, 6, 1013.

Tocantins, L. M. (1938). Medicine, Baltimore, 17, 155.

Waldo, A. L. \& Zipf, R. E. (1955). Cancer Res. 8, 187.

Weil-Malherbe, H. \& Bone, H. D. (1954). Nature, Lond., 174, 557.

Whitby, L. E. H. \& Britton, C. J. C. (1957). Disorders of the Blood, p. 713. London: Churchill.

Wintrobe, M. M. (1956). Clinical Haematology, 3rd ed. London: Henry Kimpton.

Wolbach, S. B. \& Howe, P. R. (1926). Arch. Path. (Lab. Med.) 1, 1.

\title{
Thetin-Homocysteine Transmethylase
}

\section{SOME FURTHER CHARACTERISTICS OF THE ENZYME FROM RAT LIVER}

\author{
By G. A. MAW \\ Department of Biochemistry, St Thomas's Hospital Medical School, London, S.E. 1
}

(Received 11 February 1958)

In previous communications (Maw, 1955, 1956) it was shown that as the enzymic methylation of homocysteine by dimethylthetin, $\left(\mathrm{CH}_{3}\right)_{2} \stackrel{+}{\mathrm{S}} \cdot \mathrm{CH}_{2} \cdot \mathrm{CO}_{2}^{-}$, at $\mathrm{pH} 7 \cdot 4$ involves the appearance of one proton for each molecule of methionine formed, the reaction can therefore be followed manometrically in a bicarbonate medium by measuring the carbon dioxide evolved. The enzyme responsible has been named thetin-homocysteine transmethylase, and has been partially purified from rat liver. The effect on the activity of the rat-liver transmethylase of varying the concentrations of the two substrates at $\mathrm{pH} \mathbf{7 \cdot 4}$ has been studied.

The present paper deals with some further characteristics of the enzyme. A brief survey of its substrate specificity has been made, and the effects on its activity of metal ions and a number of the more common enzyme inhibitors have been examined. Homocysteine is specifically required as a methyl acceptor. This is in contrast with the less specific requirement for a methyl donor, for in addition to dimethylthetin chloride nine other sulphonium salts have so far been shown to have some activity as methyl donors.

Some properties of the thetin-homocysteine transmethylase from pigeon liver, including its inhibition by mercaptoacetate (thioglycollate), have been briefly reported by Sloane, Boggiano, Coulomb \& Hutchings (1956), and Durell \& Anderson (1956) have described the characteristics of the enzyme from horse liver. In these studies enzymic activity was followed by colorimetric determination of the methionine formed. During the completion of the experiments reported here, Durell, Anderson \& Cantoni (1957) published details of the purification of the horse-liver transmethylase, in which methionine determinations were used as a measure of enzymic activity. Many of the characteristics of the enzyme described by these workers are in substantial agreement with those given below for the rat-liver enzyme.

\section{MATERIALS AND METHODS}

Substrates. The various thetins under study were prepared in the form of their chlorides or bromides by interaction of the corresponding chloro- or bromo-fatty acids with the appropriate thio ether (see Maw, 1953). Sulphocholine iodide (2-hydroxyethyldimethylsulphonium iodide) was prepared according to the method of Maw \& du Vigneaud $(1948 c)$. The methyl ester of dimethylthetin iodide was obtained by the interaction of methyl methylthioacetate with methyl iodide. The methionine methylsulphonium chloride used was a gift from Professor F. Challenger, to whom the author wishes to express his thanks.

DL-Homocysteine was prepared by the reduction of DLhomocystine with sodium in liquid ammonia (Riegel \& du Vigneaud, 1935-36).

Manometric procedure. The preparation of active fractions of thetin-homocysteine transmethylase from rat liver has been described in a previous communication (Maw, 1956). An account of the manometric method used to study the transmethylase has also been given in this earlier paper. 
Solutions of substrates and other substances to be added to the enzyme preparation were prepared in $0.02 \mathrm{M}$-sodium bicarbonate solution. The thetins and other acidic compounds were first neutralized with dilute aqueous sodium hydroxide and the volume then made up with $0.04 \mathrm{M}$ sodium bicarbonate solution and water so as to give a final bicarbonate concentration of $0.02 \mathrm{M}$. The volume of enzyme preparation added to the side arm of each flask was $0.5 \mathrm{ml}$., unless otherwise stated, and the final volume of fluid in each flask was $2.5 \mathrm{ml}$.

Enzyme activity has been expressed in terms of the initial reaction rate, this being the volume of carbon dioxide liberated during the $10 \mathrm{~min}$. period commencing 5 min. after the enzyme has been mixed with the substrates.

\section{RESULTS}

\section{Substrate specificity}

Specificity of the enzyme towards methyl donors. In addition to dimethylthetin chloride, a number of other methylsulphonium salts have been examined for their ability to act as methyl donors to homocysteine. Their effectiveness as substrates for the transmethylase has been assessed in terms of the initial rate of evolution of carbon dioxide obtained

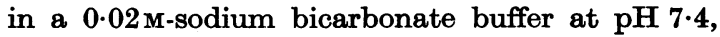
with $0.03 \mathrm{M}$-DL-homocysteine and 0.1 M-sulphonium halide (unless otherwise stated). The results obtained with these and a number of related ethylsulphonium compounds are given in Table 1, and have been expressed as percentages of the rate obtained with $0 \cdot 1 \mathrm{M}$-dimethylthetin chloride. Control determinations of the initial rate with dimethylthetin as methyl donor were included in every set of manometric experiments carried out.

Table 1. Activity of various sulphonium halides as substrates of thetin-homocysteine transmethylase

Substrates: DL-homocysteine (0.03 M), sulphonium halides $(0.1 \mathrm{M}) ; 0.5 \mathrm{ml}$. of enzyme preparation in side arm of flask; $0.02 \mathrm{M}$-bicarbonate medium; flasks gassed with $\mathrm{N}_{2}+\mathrm{CO}_{2}$ $(95: 5, \mathrm{v} / \mathrm{v})$; temp. $37 \cdot 1^{\circ}$. Results expressed as percentages of the initial rate obtained with dimethylthetin chloride.

\section{Compound}

Dimethylthetin chloride

Ethylmethylthetin chloride

Diethylthetin chloride

Dimethyl- $\alpha$-propiothetin bromide

Dimethyl- $\beta$-propiothetin bromide

Ethylmethyl- $\beta$-propiothetin bromide

Dimethyl- $\gamma$-butyrothetin bromide

Methionine methylsulphonium chloride

Sulphocholine iodide

Trimethylsulphonium chloride

Triethylsulphonium chloride

Ethyldimethylsulphonium iodide

Butyldimethylsulphonium iodide

* Corrected for $\mathrm{CO}_{2}$ retention produced by this compound.
It was not convenient to employ sulphonium salts of the same halide throughout the series of experiments. However, variation of the halide ion in several of the compounds used had no significant effect on the initial reaction rate and, further, the presence of added sodium chloride, bromide or iodide in concentrations up to $0.2 \mathrm{M}$ was also without effect.

Almost all the methylsulphonium salts tested acted as substrates, although none was more effective than dimethylthetin itself. The ability of thetins to donate methyl groups decreased with increased chain length, as seen from the rates obtained with dimethyl- $\alpha$-propiothetin, dimethyl- $\beta$ propiothetin and dimethyl- $\gamma$-butyrothetin. The rate for methionine methylsulphonium chloride was about $17 \%$ of that for dimethylthetin, but this figure is approximate, as allowance had to be made for the large retention of carbon dioxide produced by this compound under the experimental conditions employed (owing to its buffering action and to the fact that it was used in relatively high concentration). An unexpected finding was the ability of trimethylsulphonium salts to act as substrates. On the other hand, sulphocholine iodide was completely ineffective.

Diethylthetin and triethylsulphonium chlorides did not give rise to formation of carbon dioxide, indicating the lack of occurrence of a transethylation reaction under these conditions. For a compound to act as a substrate, it must clearly possess a methyl group attached to the sulphonium pcle, although only one methyl group need be present, as evidenced by the reaction rates for ethylmethylthetin and ethylmethyl- $\beta$-propiothetin, which are not far removed from those of the corresponding dimethyl compounds. Attempts to test esters of dimethylthetin as substrates have so far been unsuccessful. The methyl ester of dimethylthetin was synthesized for this purpose but was found to be too rapidly hydrolysed to dimethylthetin under the conditions of the assay to be of value as a potential substrate. Also, attempts by various methods to prepare the butyl ester of the thetin have led in every case to the formation of trimethylsulphonium salts in almost quantitative yield.

It was reported in an earlier paper (Maw, 1956) that, with dimethylthetin as the methyl donor, production of carbon dioxide by the thetin transmethylase preparations was not linear, but fell off slightly with time. In addition, the relationship between initial reaction rate and enzyme concentration was also non-linear, so making it impossible to assay the enzyme accurately by the manometric method.

With trimethylsulphonium salts as methyl donors, however, it has now been found that both the rate of formation of carbon dioxide and the 
reaction rate/enzyme concentration relationship are strictly linear, as shown in Figs. 1 and 2. At the present time, the most suitable substrate for use in the assay of the thetin transmethylase by the manometric method would therefore appear to be trimethylsulphonium chloride, despite the relatively low reaction rates obtained with this com. pound. In the series of experiments described in this paper, which have employed dimethylthetin and other thetins as substrates, the problem of the non-linear reaction rate/enzyme concentration relationship obtained with these compounds has

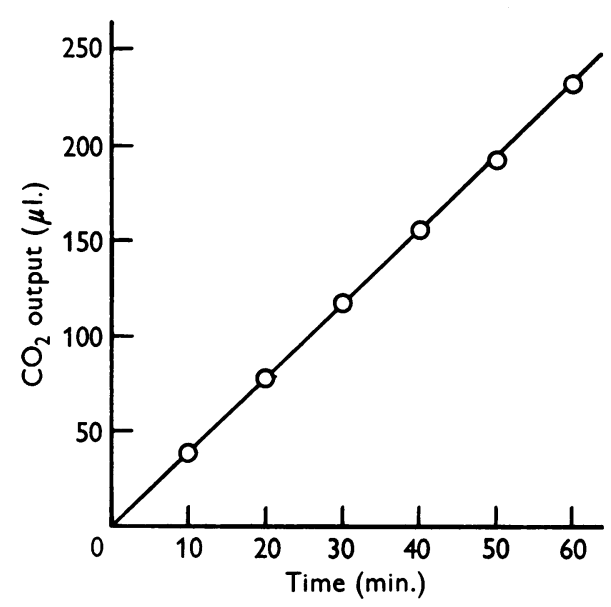

Fig. 1. Formation of carbon dioxide by a thetinhomocysteine transmethylase preparation from rat liver. Substrates: DL-homocysteine $(0.03 \mathrm{M})$, trimethylsulphonium chloride $(0.2 \mathrm{M}) ; 0.5 \mathrm{ml}$. of enzyme preparation in side arm of flask; $0.02 \mathrm{M}$-bicarbonate medium; flasks gassed with $\mathrm{N}_{2}+\mathrm{CO}_{2}(95: 5, \mathrm{v} / \mathrm{v})$; temp. $37 \cdot 1^{\circ}$.

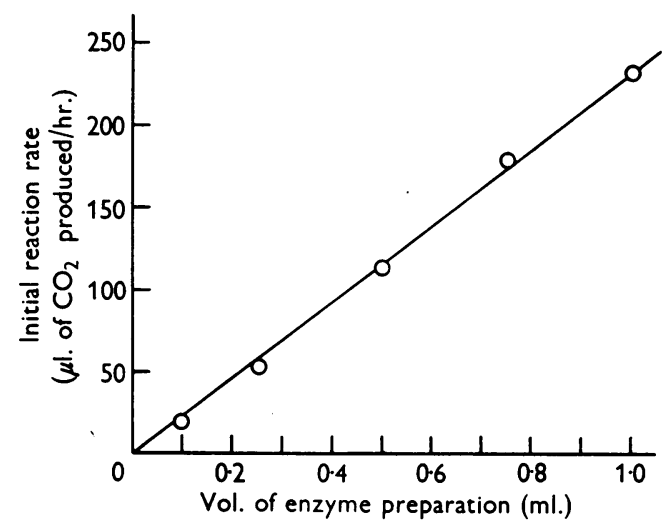

Fig. 2. Activity/concentration relationship for a thetinhomocysteine transmethylase preparation from rat liver. Substrates: DL-homocysteine $(0.03 \mathrm{M})$, trimethylsulphonium chloride (0.2 M). Other details as in Fig. 1. been circumvented by determining all reaction rates not only at fixed substrate concentrations, but also at the same enzyme concentration.

Specificity of the enzyme towards methyl acceptors. Several thiols have been tested in place of $\mathrm{DL}$ homocysteine as methyl acceptors for the thetin transmethylase, with dimethylthetin as methyl donor. Cysteamine, 2-mercaptoethanol and sodium mercaptoacetate at 0.01 and $0.03 \mathrm{M}$ were ineffective. With L-cysteine there was a small but steady production of carbon dioxide, the initial rate at $0.03 \mathrm{M}$-cysteine being equivalent to $12 \%$ of that obtained with the same concentration of DLhomocysteine. Experiments are in progress to determine whether this formation of carbon dioxide corresponds to a methylation of cysteine taking place under these conditions.

DL-Homocystine was completely ineffective as a substrate for the enzyme. This is in accord with the current belief that the disulphide must undergo reduction to homocysteine before its methylation in the animal.

\section{Inhibition of the transmethylase}

Effects of analogues. Manometric experiments have been carried out to determine whether any of the above-mentioned sulphonium compounds and thiols which are not substrates for the transmethylase act as inhibitors of the methylation of homocysteine by dimethylthetin. The concentrations of methyl donor and acceptor were 0.1 and $0.03 \mathrm{M}$ respectively. Diethylthetin and sulphocholine showed no inhibitory effects at concentrations up to $0.1 \mathrm{~m}$. The nitrogen analogue of dimethylthetin, glycine betaine, was without effect at concentrations up to $0.05 \mathrm{M}$, but consistently produced inhibitions in the region of $20 \%$ at a concentration of $0 \cdot 1 \mathrm{M}$.

Of the thiols tested, cysteine at concentrations up to $0.03 \mathrm{M}$ produced no effect other than a retention of carbon dioxide attributable to its buffering action. 2-Mercaptoethanol was also without effect. Sodium mercaptoacetate, however, acted as an inhibitor, and at a concentration of $0.03 \mathrm{M}$ caused a reduction in initial reaction rate of $26 \%$. An inhibition of the thetin-homocysteine transmethylase of pigeon liver by mercaptoacetate has been reported by Sloane et al. (1956), who found that the effect of this compound could be overcome by the addition of excess of the substrates, suggesting that the inhibition was competitive. Sodium sulphide $(0.03 \mathrm{M})$ had no inhibitory effects on the rat-liver enzyme.

Effects of metal ions. The activity of the transmethylase was markedly affected by the presence of a variety of metal ions. None of those tested caused activation, but several of the heavy-metal ions were highly inhibitory, as shown in Table 2. 
These include $\mathrm{Co}^{2+}, \mathrm{Cu}^{2+}, \mathrm{Zn}^{2+}$ and $\mathrm{Hg}^{2+}$ ions the last having a pronounced effect at $\mathrm{mm}$. $\mathrm{Fe}^{2+}$ ions were also inhibitory at this concentration. $\mathrm{Ca}^{2+}$ and $\mathbf{M g}^{2+}$ ions had negligible effects, even at $0.01 \mathrm{M}$. $\mathrm{Ag}^{+}$ions produced a $35 \%$ inhibition at $0.01 \mathrm{M}$. It is of interest that $\mathrm{K}^{+}$ions also proved to be an inhibitor and to have an effect at concentrations up to $0.01 \mathrm{M}$ comparable with that of $\mathrm{Ag}^{+}$ions. The effect of $\mathrm{K}^{+}$ions was detectable at $0 \cdot 1 \mathrm{~mm}$. In one experiment, with $\mathrm{KCl}$ at concentrations of $0.1 \mathrm{~mm}$, $1 \mathrm{~mm}, 0.01 \mathrm{M}$ and $0.1 \mathrm{M}$, the inhibitions obtained were $9,18,25$ and $29 \%$ respectively. That the effect of potassium salts was due solely to the $\mathbf{K}^{+}$ ion was indicated by identical inhibitions obtained for potassium chloride, bromide and sulphate over a wide range of salt concentrations. $\mathrm{Rb}^{+}$ions also showed inhibitory effects, although they were weaker than those of $\mathrm{K}^{+}$ions, namely $13 \%$ inhibition at $\mathrm{mm}$, and $17 \%$ at $0.01 \mathrm{M}-\mathrm{RbCl} . \mathrm{Li}^{+}$and $\mathrm{Cs}^{+}$ ions, on the other hand, showed no inhibitory effects at all the concentrations employed.

Several of the heavy-metal salts used, e.g. those of $\mathrm{Hg}^{2+}$ and $\mathrm{Ag}^{+}$, gave precipitates when added to the incubation medium. By combining with the homocysteine or with the bicarbonate present, or with both constituents, these salts might therefore have produced an apparent inhibition by altering

Table 2. Effect of various metal ions on the activity of thetin-homocysteine transmethylase

Substrates: DL-homocysteine $(0.03 \mathrm{M})$, dimethylthetin chloride $(0 \cdot 1 \mathrm{M})$; concentrations of salts added to main compartment of flask, $0.001 \mathrm{M}$ and $0.01 \mathrm{M}$; other details as for Table 1 .

\begin{tabular}{lcc} 
& $\begin{array}{c}\text { Percentage inhibition } \\
\text { produced by }\end{array}$ \\
\cline { 2 - 3 } $\mathrm{Salt}$ & $\begin{array}{c}0 \cdot 001 \mathrm{M}- \\
\text { salt }\end{array}$ & $\begin{array}{c}0 \cdot 01 \mathrm{M}- \\
\text { salt }\end{array}$ \\
$\mathrm{LiCl}$ & 0 & 0 \\
$\mathrm{KCl}$ & $24 \cdot 3$ & $28 \cdot 8$ \\
$\mathrm{RbCl}$ & $12 \cdot 6$ & $17 \cdot 3$ \\
$\mathrm{CsCl}$ & 0 & 0 \\
$\mathrm{CuSO}$ & $10 \cdot 2$ & 100 \\
$\mathrm{AgNO}_{3}$ & $17 \cdot 2$ & $34 \cdot 8$ \\
$\mathrm{CaCl}$ & 0 & 0 \\
$\mathrm{MgCl}_{2}$ & 0 & 0 \\
$\mathrm{ZnCl}_{2}$ & $16 \cdot 1$ & 100 \\
$\mathrm{HgCl}_{2}$ & $63 \cdot 3$ & 100 \\
$\mathrm{MnCl}_{2}$ & 0 & $24 \cdot 8$ \\
$\mathrm{FeSO}_{4}$ & $34 \cdot 4$ & $48 \cdot 4$ \\
$\mathrm{CoCl}_{2}$ & $9 \cdot 8$ & $85 \cdot 8$
\end{tabular}

the buffering power of the medium or by reducing the concentration of methyl acceptor. Experiments have shown, however, that even if the addition of a heavy-metal salt at $0.01 \mathrm{~m}$ caused the bicarbonate concentration to be halved or the homocysteine concentration to be reduced by onethird, the maximum reduction in rate to be expected would be no more than about $12 \%$, which is very much less than the inhibitions actually observed. Further evidence that the effect of these metal ions is primarily on the enzyme rather than on the medium or the substrates was obtained by adding the appropriate salts to the enzyme in the side arm of each Warburg flask at the beginning of the experiment. The enzyme was thus incubated with a concentrated solution of the metal salt for a preliminary period of about $20 \mathrm{~min}$. before it was mixed with the substrates and the main bulk of the medium. The degree of inhibition obtained in these circumstances was the same as that observed when the salts were added initially to the medium and substrates. This finding may also be taken to indicate that the substrates afford the enzyme no protection against the effects of heavy-metal ions.

Effects of some other enzyme inhibitors. Certain of the more commonly-used enzyme inhibitors were tested for their effects on the transmethylase, with dimethylthetin acting as the methyl donor. Sodium azide, sodium cyanide and sodium fluoride produced no inhibitory effects at concentrations up to $0.01 \mathrm{M}$. Ethylenediaminetetra-acetic acid (EDTA) was also without effect at concentrations up to $2 \mathrm{~mm}$. With the carbonyl reagents hydroxylamine and phenylhydrazine no effects were observed at a concentration of $\mathrm{mm}$, while at $0.01 \mathrm{M}$ the two compounds produced inhibitions of 32 and $18 \%$ respectively. Semicarbazide caused no significant inhibition at either concentration.

In testing the effect of iodoacetic acid on the enzyme, allowance had to be made for the rapid non-enzymic reaction which takes place between the compound and the thiol group of homocysteine. This reaction reduces the concentration of methyl acceptor, but at the same time liberates protons and so results in the formation of carbon dioxide from the bicarbonate buffer. The iodoacetate was consequently added initially to the enzyme in the side arm of the Warburg flask, so that the enzyme was in contact with the inhibitor for a period of at

Table 3. Effect of iodoacetic acid on the activity of thetin-homocysteine transmethylase

Substrates: DL-homocysteine $(0.03 \mathrm{M})$, dimethylthetin chloride $(0.1 \mathrm{M})$; other details as for Table 1 .

Concn. of iodoacetic acid (mM)

$0 \cdot 1$

1

10

Enzymic
reaction rate
$94 \cdot 7$
$94 \cdot 7$
$94 \cdot 7$

Expected
combined rate
95
$99 \cdot 4$
$175 \cdot 4$

Observed
rate
$98 \cdot 4$
$102 \cdot 7$
$147 \cdot 5$

Percentage inhibition

$$
\overline{16}
$$


least $20 \mathrm{~min}$. before mixing with the substrates took place. The initial reaction rate obtained under these conditions is the sum of the rates of the simultaneous non-enzymic and enzymic reactions. If iodoacetate were to produce any inhibitory effect on enzyme activity, this observed initial rate should therefore be less than the sum of the nonenzymic reaction rate and the rate of the enzymic reaction in the absence of iodoacetate. By using three different iodoacetate concentrations, as shown in Table 3, only at the highest inhibitor concentration $(0.01 \mathrm{M})$ was the observed rate less than the sum of the two component rates.

Although these results are not conclusive, they do suggest that the activity of the transmethylase is relatively insensitive to the action of this inhibitor.

\section{DISCUSSION}

A comparison may be made of the results obtained in the present series of experiments with previous observations on the metabolism of sulphonium compounds in the intact rat. Dimethylthetin and dimethyl- $\beta$-propiothetin are efficient methyl donors in vivo, judged by their ability to support the growth of rats on methyl-deficient diets (Maw \& du Vigneaud, $1948 a, b)$. Both compounds also undergo extensive oxidation to inorganic sulphate in the rat (Maw, 1953). This is explained by their ability to act as substrates for the thetin-homocysteine transmethylase, for there is evidence that the initial step in their oxidation is a demethylation (Maw, 1954). The variable activity of ethylmethylthetin in vivo may be contrasted with its effectiveness as a methyl donor in enzyme experiments. This difference in behaviour may be due to factors which are operative in vivo, e.g. the toxicity of the demethylated product of the thetin, ethylthioacetic acid.

The sulphonium salt, sulphocholine chloride, has been found unable to serve as an efficient source of methyl groups in vivo (Maw \& du Vigneaud, 1948c). On the other hand, in tissue preparations under aerobic conditions this compound has been shown to be involved in the methylation of homocysteine (Dubnoff, 1949) and, further, in the intact rat it is to some extent oxidized to sulphate (Maw, 1953). The ineffectiveness of sulphocholine as a substrate for the thetin transmethylase argues against its participation as a direct methyl donor, but is in accord with the belief that this compound undergoes a preliminary oxidation to dimethylthetin as a first step in its metabolism (Dubnoff, 1949; Maw, 1953).

The finding that methionine methylsulphonium chloride is a substrate for the transmethylase accounts for its ability to act in vivo in place of methionine. In view of its wide occurrence in vegetables (Challenger \& Hayward, 1954; McRorie et al. 1954), this compound must therefore be regarded as a potential, if minor, source of dietary methyl groups for the animal. Durell et al. (1957) have recently drawn attention to the high concentration of thetin-homocysteine transmethylase in horse liver, and have found that $S$-adenosylmethionine does not act as a substrate for the enzyme. This raises the possibility that methionine methylsulphonium salts, and perhaps also the simpler thetins, may be of more importance in animal metabolism than was originally supposed.

No evidence has yet been obtained to suggest. that the transmethylase possesses a prosthetic group. The enzyme resists prolonged dialysis, is not markedly affected by carbonyl reagents and is unaffected by the presence of EDTA, and no activation has been observed with a variety of metal ions. Its mode of action has also not been established. Two possible mechanisms have been envisaged and are proposed here. The first is that one of the active centres of the enzyme may consist of a tertiary nitrogen atom or a bivalent sulphur atom which acts as the initial acceptor of methyl groups from methylsulphonium compounds by participating in a group transfer reaction. This is shown below, assuming the active centre $(\mathrm{N} \equiv E)$ to be tertiary nitrogen:

$$
\mathrm{R} \cdot \stackrel{+}{\mathrm{S}}\left(\mathrm{CH}_{3}\right)_{2}+\mathrm{N} \equiv E \rightarrow \mathrm{R} \cdot \mathrm{S} \cdot \mathrm{CH}_{3}+\mathrm{CH}_{3} \cdot \stackrel{+}{\mathrm{N}} \equiv E
$$

The quaternary-ammonium (or sulphonium) form of the enzyme would then transfer the methyl group to homocysteine as follows:

$$
\begin{aligned}
& \mathrm{CH}_{3} \cdot \stackrel{+}{\mathrm{N}} \equiv E+\mathrm{HS} \cdot \mathrm{R}^{\prime} \rightarrow \mathrm{N} \equiv E+\mathrm{CH}_{3} \cdot \stackrel{+}{\mathrm{S}} \mathrm{H} \cdot \mathrm{R}^{\prime} \\
& \left(\rightarrow \mathrm{CH}_{3} \cdot \mathrm{S} \cdot \mathrm{R}^{\prime}+\mathrm{H}^{+}\right)
\end{aligned}
$$

The numerous tissue constituents containing tertiary nitrogen which might be capable of acting as initial acceptors include histidine, nicotinamide and other heterocyclic structures, as well as dimethylethanolamine and related compounds.

An alternative mechanism involves the preliminary combination of the enzyme with homocysteine. This is a more likely possibility in view of the high specificity of the enzyme for this substrate. The role of the enzyme would be to bind the homocysteine, presumably through its amino and carboxyl groups, and by bringing the thiol group into close proximity with some basic group to induce liberation of a proton. This would be followed by a thiolytic attack of the mercaptide ion thus formed on the methyl carbon atom of a methyl-donor substrate. The two schemes differ in that the first requires the combination of enzyme with methyl donor as the preliminary step, whereas the second requires an initial combination between enzyme and methyl acceptor. These two possibilities correspond respectively to the double and 
single displacement mechanisms for enzymic substitution reactions recently discussed by Koshland (1954).

\section{SUMMARY}

1. The ability of a number of methylsulphonium and ethylsulphonium salts related to dimethylthetin to act as substrates for partially purified preparations of thetin-homocysteine transmethylase from rat liver has been examined. Dimethylthetin is the most effective methyl donor so far investigated.

2. Trimethylsulphonium chloride acts as a substrate for the enzyme, and gives rise to a linear reaction rate and a linear enzyme activity/concentration relationship. This compound has therefore been considered as a suitable substrate for the manometric assay of the transmethylase.

3. Homocysteine was the only effective methyl acceptor among the thiols tested, although some evidence was obtained to suggest that L-cysteine might be acting as a substrate.

4. None of the metal ions which were tested activated the enzyme; several heavy-metal ions and potassium ions were inhibitory. Several other commonly-used inhibitors had no effect on the enzyme.

5. Possible mechanisms for the participation of the enzyme in the transmethylation reaction have been proposed.
It is a pleasure to thank Mr Norman Allin for technical assistance during the course of this work and Dr M. B. Thorn for many helpful comments. Grateful acknowledgement is also made to the Endowment Fund of St Thomas's Hospital for aid in the purchase of materials and equipment.

\section{REFERENCES}

Challenger, F. \& Hayward, B. J. (1954). Chem. \& Ind.p. 729. Dubnoff, J. W. (1949). Arch. Biochem. 22, 478.

Durell, J. \& Anderson, D. G. (1956). Fed. Proc. 15, 245.

Durell, J., Anderson, D. G. \& Cantoni, G. L. (1957). Biochim. biophys. Acta, 26, 270.

Koshland, D. E. jun. (1954). The Mechanism of Enzyme Action, p. 608. Ed. by McElroy, W. D. \& Glass, B. Baltimore: The Johns Hopkins Press.

McRorie, R. A., Sutherland, G. L., Lewis, M. S., Burton, A. D., Glazener, M. R. \& Shive, W. (1954). J. Amer. chem. Soc. 76, 115.

Maw, G. A. (1953). Biochem. J. 55, 42.

Maw, G. A. (1954). Biochem. J. 58, 665.

Maw, G. A. (1955). Biochem. J. 60, xxxii.

Maw, G. A. (1956). Biochem. J. 63, 116.

Maw, G. A. \& du Vigneaud, V. (1948a). J. biol. Chem. 174, 381.

Maw, G. A. \& du Vigneaud, V. (1948b). J. biol. Chem. 176, 1029.

Maw, G. A. \& du Vigneaud, V. (1948c). J. biol. Chem. 176, 1037.

Riegel, B. \& du Vigneaud, V. (1935-36). J. biol. Chem.112, 149.

Sloane, N. H., Boggiano, E. M., Coulomb, B. \& Hutchings, B. L. (1956). Fed. Proc. 15, 357.

\title{
Further Observations on the Oxidation of Di-iodotyrosine Derivatives
}

\author{
By ROSALIND PITT-RIVERS AND A. T. JAMES \\ National Institute for Medical Research, Mill Hill, London, N.W. 7
}

(Received 20 February 1958)

It has already been shown by one of us (PittRivers, 1948) that the conversion of di-iodotyrosine into thyroxine in vitro is enhanced when both the amino and carboxyl groups of di-iodotyrosine are blocked; the first compound of this nature to be studied was $N$-acetyl-DL-di-iodotyrosyl-L-glutamic acid, which gave rise to the corresponding thyroxine derivative in yields up to $35 \%$, calculated on amount of di-iodotyrosine derivative lost. In the present paper, the formation in vitro of several new thyroxine derivatives is described. At the same time, the side chain lost from one di-iodotyrosine molecule during the coupling reaction has been identified.

\section{EXPERIMENTAL}

The acetyl-DL-di-iodotyrosyl-amino acid derivatives were all formed from 4-(3:5-di-iodo-4-acetoxybenzyl)-2-methyloxazolone and the required amino acid, as in the synthesis of $N$-acetyl-DL-di-iodotyrosylglutamic acid (Pitt-Rivers, 1948) and will not, except for $N$-acetyl-DL-di-iodotyrosyl$\epsilon-N$-( $\alpha-N$-acetyl)-lysine, be described in detail; the aerobic incubation of this compound, which gave the highest yields of the thyroxine derivative, was extensively studied and led to the recognition of the $\mathrm{C}_{3}$ residue split off from the di-iodotyrosine molecule.

\section{$\mathrm{N}$-Acetyl-DL-di-iodotyrosyl- $\epsilon-\mathrm{N}-(\alpha-\mathrm{N}$-acetyl)-L-lysine}

4 - (3:5 - Di - iodo - 4 - acetoxybenzyl) - 2 - methyloxazolone $(20 \mathrm{~g}$.$) was dissolved in dry acetone (170 \mathrm{ml}$.) and chilled in an ice bath. $\alpha-N$-Acetyl-lysine (Neuberger \& Sanger, 1943) (6 g.) dissolved in $\mathrm{N}-\mathrm{NaOH}(32 \mathrm{ml}$.) was added and the reaction was allowed to proceed for $14 \mathrm{hr}$. Most of the acetone was then removed under diminished pressure, the solution was diluted with water, and acidified with $\mathrm{HCl}$. After chilling, the product was collected, washed with water and crystallized from $50 \%(v / v)$ ethanol. The compound crystallized in thin leaflets, m.p. 170-171 ${ }^{\circ}$; the yield was $88 \%$ of the theoretical (Found: N, 6.4; I, 39.4. $\mathrm{C}_{19} \mathrm{H}_{25} \mathrm{O}_{6} \mathrm{~N}_{3} \mathrm{I}_{2}$ requires $\mathrm{N}, 6 \cdot 5 ; \mathrm{I}, 39 \cdot 4 \%$ ). 